\title{
Supporting Information: Investigations on the temperature dependent interaction of water vapor with tin dioxide and its implications on gas sensing
}

David Degler ${ }^{1, *}$, Benjamin Junker ${ }^{2}$, Frank Allmendinger ${ }^{1}$, Udo Weimar $^{2}$ and Nicolae Barsan ${ }^{2}$

${ }^{1}$ Faculty of Industrial Technologies, Furtwangen University, D-78532 Tuttlingen, Germany

2 Institute of Physical and Theoretical Chemistry and Centre for Light-Matter Interaction, Sensors \& Analytics (LISA ${ }^{+}$), University of Tübingen, D-72076 Tübingen, Germany

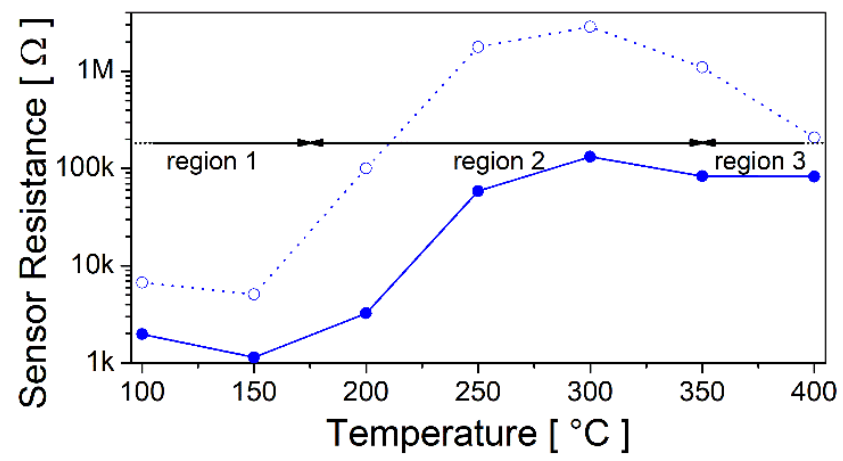

Figure S1. Sensor resistance in low humidity $(<10 \mathrm{ppm} \mathrm{H} 2 \mathrm{O})$ and humid air $(10 \% \mathrm{RH})$. 

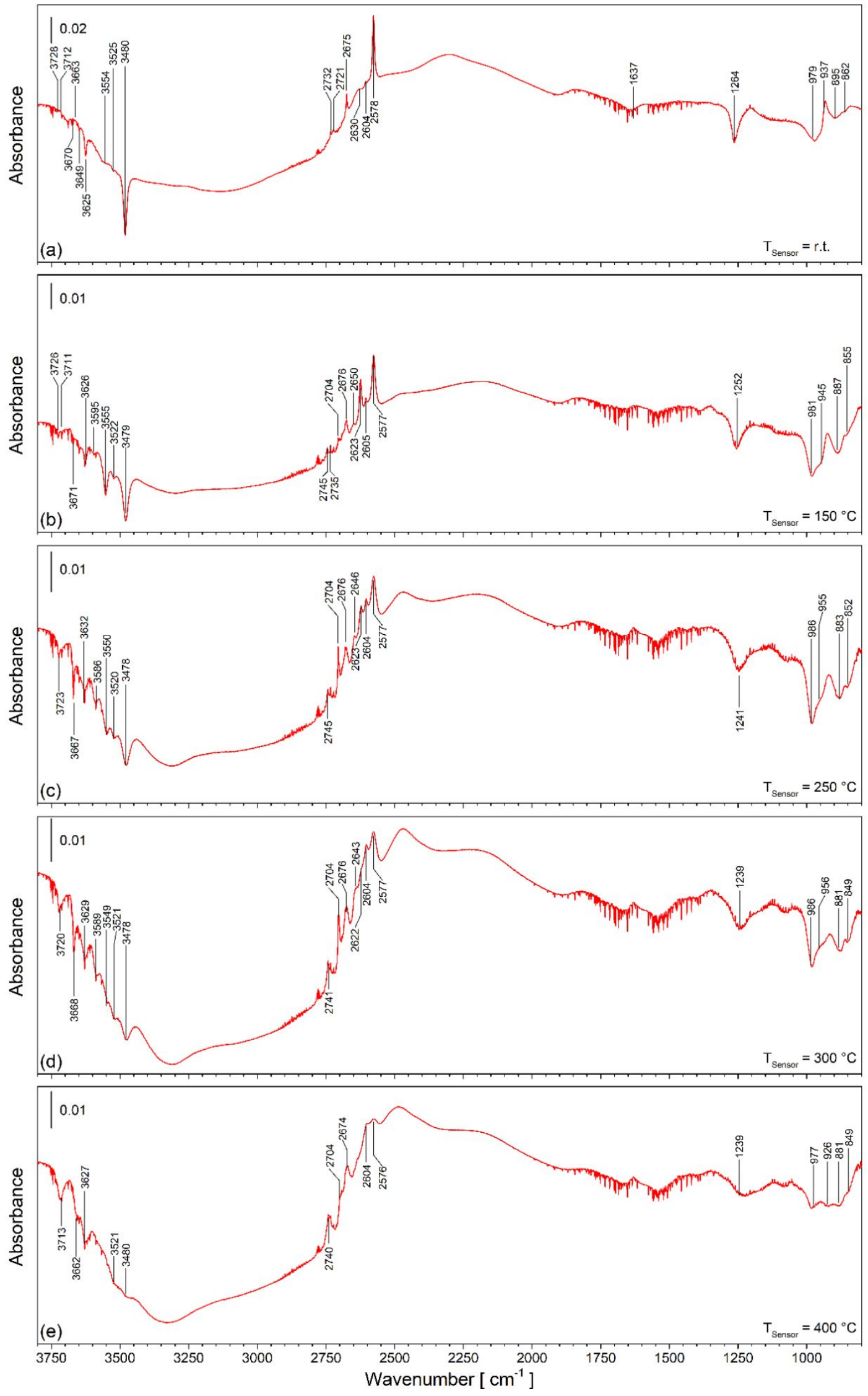

Figure $\mathrm{S} 2 . \mathrm{H}_{2} \mathrm{O}-\mathrm{D}_{2} \mathrm{O}$ steady change exchange spectra calculated from the $\mathrm{H}_{2} \mathrm{O}$ and $\mathrm{D}_{2} \mathrm{O}$ spectra shown in Figure 4 at room temperature (a), $150{ }^{\circ} \mathrm{C}$ (b), $250{ }^{\circ} \mathrm{C}$ (c), $300{ }^{\circ} \mathrm{C}$ (d) and $400{ }^{\circ} \mathrm{C}$ (e). These spectra provide a better overview of water-related species found on the $\mathrm{SnO}_{2}$ surface during water exposure. 


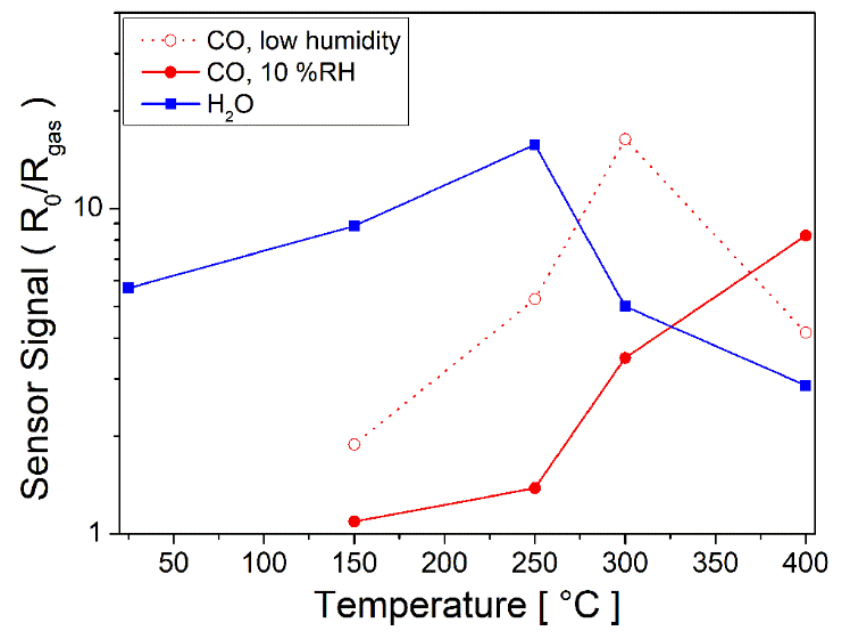

Figure S3. Sensor signals calculated from the resistance measurements during operando DRIFTS spectroscopy (Figure 4) for $\mathrm{H}_{2} \mathrm{O}$ (blue), as well as for $\mathrm{CO}$ (red, empty symbols) in low humidty $\left(<10 \mathrm{ppm} \mathrm{H}_{2} \mathrm{O}\right.$ ) and humid air (red, filled symbols). 